\title{
Francisco Dubert-García, Vítor Míguez e Xulio Sousa (eds.), Variedades lin- güísticas en contacto na Península Ibérica, Santiago de Compostela, Consello da Cultura Galega, 2020, 220 páxinas.
}

Data de recepción: 07/08/2020 | Data de aceptación: 09/09/2020

O contacto entre linguas é unha realidade universal. De feito, as causas coloniais e comerciais, o tráfico de escravos, as guerras etc., propiciaron un continuo contacto entre as distintas falas que trouxo consigo situacións concretas como o bilingüismo, a diglosia ou as interferencias. Precisamente, a sociolingüística, como disciplina pertencente ás ciencias da linguaxe, dedica unha parte do seu interese ao que comunmente coñecemos como "linguas en contacto", termo proveniente da tradución do libro de Weinreich (1953) Languages in Contact. Se a fala é unha actividade social e cognitiva, a unidade de análise central debe ser a comunidade lingüística. É importante, a este respecto, ollarmos o número de linguas que existen na actualidade, máis de 6000 en menos de 200 estados, e recordarmos a importante función que a lingua e a fala teñen na constitución de identidades comunitarias / sociais / locais / nacionais e de como estas impactan na nosa vida pública e alteran o mapa do mundo, até o punto de chegaren a se declarar conflitos por diverxencias lingüísticas. Por tanto, falarmos de monolingüísmo como normalidade lingüística resultaría unha falacia.

Na Península Ibérica, como acontece no resto de territorios en que conviven varias linguas, prodúcese o contacto entre as diversas variedades lingüísticas adscritas a cada unha das linguas históricas (galego, castelán, asturiano, portugués, vasco, aranés, catalán, aragonés etc.). No entanto, como é sabido, a diversidade lingüística é considerada, ás veces, unha maldición e un castigo divino, como xa se vén documentando desde a antigüidade co mito de Babel. Resulta evidente que estas visións negativas teñen a súa orixe en preconceptos lingüísticos de sobra analizados noutros manuais. Non obstante este feito, as situacións de contacto entre linguas son unha parte significativa delas e danse na maioría de falantes e en diversos momentos históricos dunha lingua viva.

Neste sentido, a saída do prelo no último cuartel de 2020 de Variedades lingüísticas en contacto na Península Ibérica conforma unha selección de contributos que analizan as situacións de contacto en comunidades próximas cultural e xeograficamente no ámbito peninsular. Este libro, editado por Francisco Dubert-García, Vítor Míguez e Xulio Sousa, e publicado dentro da colección "Ensaio \& Investigación” do Consello 
da Cultura Galega, recolle unha serie de artigos que achegan información sobre as diferentes posibilidades de contacto entre variedades e desde diversas perspectivas. O volume serve, outrosí, como unha panorámica que nos desloca desde unha beira a outra da Península e que permite observarmos unha grande parte do seu patrimonio lingüístico.

Así, por unha parte, analízanse linguas moi próximas como é o caso do mirandés e o portugués, estudados por Alberto Gómez Bautista, ou o caso do asturiano co castelán, por Ramón de Andrés. Na mesma liña mais nun contexto máis próximo a nós temos os traballos realizados por Alba Aguete Cajiao, que repara na fonoloxía do galego a respecto do seu contacto co castelán, e por Victoria Vázquez Rozas, que revisa os efectos na sintaxe do castelán do seu contacto co galego. Por outra parte, o traballo de Matilde Vida-Castro analiza o contacto entre variedades dunha mesma lingua (dialectos andaluces e castelán estándar). Por seu turno, tamén se valora o contacto entre linguas de tipoloxía diferente como é o caso do castelán e o éuscaro a través do estudo asinado por Sara Gómez Seibane. Por último, Carsten Sinner atende ao contacto entre o castelán e o catalán e con este pano de fondo fai unha reflexión crítica a respecto dos métodos e dos logros deste tipo de traballos.

Entrando na materia en debate, no primeiro dos traballos, intitulado "Opinión, mediación y generalización como retos de la lingüística de contacto. Ejemplos del estudio del contacto entre castellano y catalán” (páxs. 17-44), Sinner inaugura o volume e coloca o foco no estudo sobre as influencias mutuas entre o castelán e o catalán en Cataluña desde unha perspectiva metodolóxica, isto é, proporciona unha mirada crítica e, en certa medida, historiográfica dos estudos de contacto lingüísticos en Cataluña e analiza o método empregado nalgúns dos principais traballos. Neste sentido, como ben argumenta o autor, os erros metodolóxicos detectados débense a unha xeneralización no momento de clasificar e categorizar os informantes segundo o seu perfil social e lingüístico. Consecuentemente, a validez dos resultados do estudo vese cuestionada por esa xeneralización excesiva. No entanto, advirte que esta problemática non só concirne a estudos de contacto entre castelán e catalán, mais son un reto universal nos estudos de lingüística.

O valor dos materiais e do método faise palpábel no segundo dos traballos: repárese en "Contacto de lenguas en Asturias: 'amestáu' y castellano" (páxs. 47-79), onde De Andrés percorre un terreo pouco explorado sobre o contacto do asturiano e do castelán en Asturias e achega un aparello conceptual que fai operativo o concepto de mestura de linguas e que evidencia o contínuum dialectal ou unha continuidade en graos entre o asturiano e o castelán, prestando moita atención ao papel que xoga a variedade hibrida amestáu. Por súa vez, o autor reflexiona sobre as principais nocións da lingüística variacionista e proba as vantaxes de conxugar as perspectivas 
glotolóxica e perceptiva en investigacións deste tipo. Consecuentemente, no seu estudo analiza o desgaste que sofren as variedades do asturiano e chega a conclusións moi reveladoras ao ter en conta a distinción entre as interferencias e as converxencias entre ambas as linguas.

Saltando dun espazo xeográfico a outro, Gómez Bautista, no seu traballo intitulado "Consecuencias do contacto lingüístico entre mirandés e portugués" (páxs. 81-100), analiza os fenómenos lingüísticos que se produciron a través do convivio das dúas linguas que coexisten desde hai séculos no extremo nordeste de Portugal: o mirandés (unha variedade de orixe ástur-leonesa falada nas Terras de Miranda) e o portugués. O contacto lingüístico entre ambas as linguas obxecto de análise, embora veña de vello, é asimétrico debido á relación que entre elas se estabeleceu: o portugués, lingua oficial, e mirandés, falado pola maior parte parte da poboación, mais só nos contextos familiares. Como se torna obvio deducirmos, esta situación é semellante ao caso do galego, xa que se observa o contacto entre unha lingua minorizada, neste caso, o mirandés, e outra lingua de prestixio, o portugués. Consecuentemente, tales factores provocan que unha das linguas sexa máis vulnerábel á interferencia da lingua dominante. Unha vez feitos estes apuntamentos, o autor analiza algúns fenómenos que son o resultado do contacto lingüístico naquel territorio no plano ortográfico, fónico e fonolóxico, léxico e morfosintáctico, e estabelece até que punto a influencia do portugués estándar, comunmente denominado portugués padrão, pode ser determinante no devir da evolución do mirandés.

O cuarto dos traballos, que leva por título "Patrones de convergencia en lenguas tipológicamente no relacionadas: lengua vasca y castellano" (páxs. 101-125), está asinado por Gómez Seibane e nel a autora quere afondar sobre a converxencia entre sistemas lingüísticos tipoloxicamente moi distantes, como é o caso dos que centran o capítulo. Cómpre destacarmos que o éuscaro é a única lingua ibérica que non é de raíz romance e que a súa estrutura é completamente diferente non só á do castelán, senón tamén a calquera outra lingua peninsular. Por tanto, tal e como indica a autora, o éuscaro non forma parte do contínuum lingüístico ibérico por ser unha lingua que ficou illada como resultado de movementos étnicos, políticos e históricos que se sucederon arredor. Co propósito de nos mostrar as interferencias mutuas entre ambos os idiomas, Gómez Seibane parte das principais características tipolóxicas destas dúas linguas en contacto dunha forma sintética para, a seguir, explorar os parámetros internos e externos que dan lugar ás interferencias partindo do contexto sociocultural e histórico en que aconteceu o dito contacto. Esa vontade de contextualizar as mudanzas lingüísticas e sintetizar o marco teórico responde á intención de demostrar que incluso sistemas lingüísticos moi afastados poden chegar a se influír mutuamente. As mudanzas lingüísticas tradicionalmente descritas como produto da súa convivencia poñen o foco no feito de que a distancia tipolóxica 
entre linguas non impide os intercambios de estrutura gramatical. A este respecto, fornecese ao público lector de exemplos concretos de fenómenos de converxencia entre ambos os sistemas, que ilustran a mutua influencia de linguas afastadas estruturalmente; por unha banda, móstranse as características lingüísticas do castelán do País Vasco e, por outra, os fenómenos de converxencia no éuscaro.

De igual modo, resulta interesante o contributo que fai Vida-Castro no traballo que leva por nome "Procesos de estandarización y divergencia dialectal en las variedades meridionales del español de España" (páxs. 127-154). Nel, a autora investiga a confluencia de diferentes variedades dunha mesma lingua en espazos urbanos; concretamente, analiza como a pronuncia do castelán estándar interaxe coas pronuncias dialectais do andaluz nos espazos urbanos da cidade de Málaga producindo fenómenos de koineización, isto é, o proceso polo cal unha nova variedade dunha lingua emerxe da mestura, nivelación e simplificación de diferentes dialectos. A este respecto, cómpre sinalarmos que este estudo fai parte do traballo desenvolvido polo grupo de investigación Vernáculo Urbano Malagueño (VUM) sobre as variedades lingüísticas da cidade de Málaga, especialmente dentro dos planos fonético-fonolóxico, sintáctico e léxico. O contributo da autora abranxe os procesos internos e externos que activan a converxencia e a diverxencia dialectais que afectan as principais variedades dialectais dunha mesma lingua, as cales parecen proxectar a identidade combinada dos seus falantes. Os procesos de estandarización e koineización que presenta a autora vense motivados por factores relacionados cunha relativa complexidade socioeconómica que comprometen o sistema de sibilantes, de tal forma que algúns trazos moi salientábeis das variedades andaluzas son substituídos por formas próximas ao estándar, en canto outros chegan a se constituír como formas de expresión locais que dan pé a fenómenos de diverxencia dialectal.

Os últimos traballos deste volume afondan na cuestión galega. Por unha banda, Aguete Cajiao en "Contacto de linguas e variedades na emerxencia de novos modelos de vocalismo galego" (páxs. 155-193) presenta as conclusións obtidas a través dun estudo experimental con alumnado universitario cuxa lingua inicial e habitual é o galego. O dito estudo tiña como finalidade analizar os fenómenos de variación existentes no vocalismo galego e debuxar unha panorámica sobre os posíbeis factores internos, externos e extralingüísticos que puidesen estar motivando a variación do sistema vocálico da lingua, vencellados fundamentalmente á procedencia dos falantes e ao efecto do contacto co español. Neste sentido, tras presentar as principais características fonolóxicas e fonéticas das vogais galegas, os resultados obtidos da descrición acústica que nos achega a autora mostran a existencia de varios modelos de vocalismo. Por unha parte, demostra a presenza de dous modelos de vocalismo tónico. O primeiro destes corresponde ao vocalismo 
tónico descrito para o galego tradicional e o segundo coincide co vocalismo tónico do castelán. Esa distinción, segundo os datos obtidos, demostra a existencia de varios modelos de vocalismo dependentes da procedencia (rural ou urbana) dos falantes. Alén diso, os resultados tamén deitan luz sobre a relevancia do hábitat de residencia dos falantes no mantemento da oposición entre as vogais medias altas e medias baixas. Consecuentemente, podemos falar da presenza dun modelo vocálico conservador, propio de falantes rurais e en certa medida impermeábel á influencia fonética do castelán, e un modelo innovador, producido por falantes urbanos e converxente coa lingua dominante. No entanto, a autora tamén apunta que o hábitat de residencia non é o único factor que motiva esta variación, xa que cómpre engadirmos a variación situacional que favorece o uso do sistema innovador que segue a tendencia á converxencia do vocalismo galego do castelán.

De parecido xeito, Vázquez Rozas, no seu traballo intitulado "Había + participio no español falado en Galicia: un estudo de corpus” (páxs. 195-220), analiza o caso galego, mais non desde unha perspectiva fonético-fonolóxica, senón gramatical a través do estudo dos tempos verbais. É ben sabido que o español falado na Galiza adoita caracterizarse, entre outros fenómenos, pola ausencia de formas verbais compostas pola influencia do galego. Con todo, esta situación documentada en diversas publicacións non é unha realidade a día de hoxe, pois o uso de tempos compostos está estendido entre os falantes de español na Galiza. A mostra fornécese dun corpus oral estratificado socialmente e compara os usos da forma composta había + participio, mais tamén doutras dúas relacionadas como son cantara e cantase. As conclusións que se obteñen con esta investigación revelan o predominio da forma composta sobre a simple para a expresión de valores temporais de antepretérito, pretérito e copretérito de indicativo, ben como unha distribución por sociolectos. Os motivos que condicionan este fenómeno débense moi probabelmente á influencia da norma prescritiva entre os falantes cun maior nivel de estudos. Porén, os usos de habia + participio como pretérito e copretérito son unha peculiaridade do español da Galiza, en que a lingua de poder se ve afectada pola lingua minorizada. Así pois, o volume pecha con novos datos e argumentos para o debate gramatical.

Estas son, grosso modo, as liñas xerais que se formulan en cada un dos contributos que compoñen Variedades lingüísticas en contacto na Península Ibérica e, en consecuencia, o volume ofrece unha panorámica sobre percursos de investigación que afectan as mudanzas lingüísticas entre linguas en contacto cultural e xeograficamente. Neste sentido, trátase dunha miscelánea enriquecedora que estuda procesos de interferencia lingüística motivados pola diglosia existente na Península e ofrece ao público lector interesado unha perspectiva xeral sobre os estudos actuais no campo das linguas en contacto. 


\section{Referencias bibliográficas}

Weinreich, Uriel (1953). Languages in Contact. A Haia: Mouton.

Noemi García Rodríguez 